\title{
It's a man's world: Does orthotopic liver transplantation in the elderly male confer an additional risk on survival?
}

\author{
Eoin Slattery MD MRCPI, John E Hegarty MD FRCPI, P Aiden McCormick MD FRCPI
}

E Slattery, JE Hegarty, PA McCormick. It's a man's world: Does orthotopic liver transplantation in the elderly male confer an additional risk on survival? Can J Gastroenterol 2012;26(10):697-700.

BACKGROUND: Orthotopic liver transplantation (OLT) in a wellselected population is a highly successful procedure, with one-year survival rates reported to be as high as $90 \%$. Advanced age is considered to be a contraindication. Survival rates in patients $>60$ years of age appear to be comparable with those of younger patients. However, little objective data exist on the outcomes of patients $>65$ years of age undergoing OLT.

OBJECTIVE: To review the outcomes of OLT in the Irish National Transplant Unit in patients $>65$ years of age and to compare outcomes with patients $\leq 65$ years of age. Second, to identify any factors that may provide valuable prognostic information regarding outcomes.

METHOD: Patients $>65$ years of age who underwent OLT since the inception of the National Liver Unit in 1993 were identified from a prospectively maintained database. Medical records were reviewed. Survival was compared with the overall cohort using the KaplanMeier technique. Independent variables between the two groups were assessed using logistic regression analysis.

RESULTS: Between January 1993 and December 2009, 551 patients underwent 639 transplants in the Irish National Liver Transplant Unit. Forty-three transplants were performed in 40 patients $>65$ years of age. Unadjusted one- and three-year survival rates for the elderly cohort were $77.8 \%$ and $64.5 \%$, respectively. This compared with $93 \%$ and $85 \%$, respectively, in the unselected cohort. Using Kaplan-Meier analysis, a significant benefit in survival was observed in patients $\leq 65$ years of age $(\mathrm{P}=0.017)$. Similarly, when adjusted for sex, a significant difference was noted between the groups. Male patients $>65$ years of age had poorer survival compared with their female counterparts $>65$ years of age and all patients $\leq 65$ years of age $(P=0.02)$. There was no significant difference between the groups with respect to preoperative variables such as bilirubin, creatinine and sodium levels, and Model for End-stage Liver Disease score. A significant difference was seen in male patients $>65$ years of age with more than one comorbidity, compared with female patients and male patients $\leq 65$ years of age.

CONCLUSION: Male sex was associated with poorer survival in patients $>65$ years of age undergoing OLT. Multiple comorbidities in elderly male patients should be considered a relative contraindication in patients being assessed for OLT.

Key Words: Elderly; Liver transplant; Outcomes
C'est un milieu d'hommes : la transplantation hépatique orthotopique chez les hommes âgés ajoute-t-elle un risque supplémentaire à la survie ?

HISTORIQUE : La transplantation hépatique orthotopique (THO) dans une population bien sélectionnée est une intervention très positive, dont le taux de survie au bout d'un an atteint les 90 \%. L'âge avancé est considéré comme une contre-indication. Le taux de survie chez les patients de plus de 60 ans semble comparable à celui des patients plus jeunes. Cependant, il existe peu de données objectives sur le sort des patients de plus de 65 ans qui subissent une $\mathrm{THO}$

OBJECTIF : Analyser les issues des THO à l'unité nationale irlandaise de transplantations chez les patients de plus de 65 ans et les comparer à celles des patients de 65 ans et moins. Déterminer ensuite les facteurs susceptibles de fournir de l'information pronostique précieuse au sujet des issues.

MÉTHODOLOGIE : À l'aide d'une base de données prospective, les chercheurs ont repéré les patients de plus de 65 ans qui ont subi une THO depuis la création de l'unité hépatique nationale en 1993. Ils ont analysé les dossiers médicaux et comparé la survie avec la cohorte globale au moyen de la technique de Kaplan-Meier. Ils ont évalué les variables indépendantes entre les deux groupes grâce à une analyse de régression logistique.

RÉSULTATS : Entre janvier 1993 et décembre 2009, 551 patients ont subi 639 transplantations à l'unité nationale irlandaise de transplantation hépatique. Quarante-trois transplantations ont été exécutées chez 40 patients de plus de 65 ans. Les taux de survie non rajustés au bout d'un an et de trois ans au sein de la cohorte de personnes âgées s'élevaient à 77,8 \% et à 64,5\%, respectivement, par rapport à $93 \%$ et à $85 \%$, respectivement, au sein de la cohorte non sélectionnée. Au moyen de l'analyse de Kaplan-Meier, les chercheurs ont observé d'importants avantages en matière de survie chez les patients de 65 ans ou moins $(\mathrm{P}=0,017)$. De même, après rajustement compte tenu du sexe, les chercheurs ont remarqué une différence significative entre les groupes. Les patients de sexe masculin de plus de 65 ans survivaient moins que leurs homologues de sexe féminin de plus de 65 ans et que l'ensemble des patients de 65 ans ou moins $(\mathrm{P}=0,02)$. Les chercheurs n'ont constaté aucune différence significative entre les groupes à l'égard de variables préopératoires telles que la bilirubine, la créatinine, les taux de sodium et l'indice du modèle de maladie hépatique en phase terminale. Ils ont remarqué une différence significative chez les patients de sexe masculin de plus de 65 ans ayant plus d'une comorbidité, par rapport aux patientes et aux patients de 65 ans ou moins.

CONCLUSION : Le sexe masculin s'associait à une baisse de la survie chez les patients de 65 ans ou plus qui subissaient une THO. De multiples comorbidités chez les patients âgés de sexe masculin devraient être considérées comme une contre-indication relative en cas d'évaluation en vue d'une THO.

was previously the case (1). Indeed, in the same article, Prakoso et al (1) also reported a significant increase in mortality in patients who were on the OLT wait list. While increased demand does not appear to have had a visible impact on outcomes, it has become incumbent on transplant physicians to scrutinize all potential recipients carefully to ensure proper use of a scarce and valuable resource (ie, the donated liver). reported to be as high as $90 \%$. However, liver transplantation is becoming a victim of its own success, with demand now significantly outstripping supply. This has led to longer wait times for liver transplant and the occurrence of significantly sicker patients undergoing transplant than

National Liver Transplant Unit, St Vincent's University Hospital, Dublin, Ireland

Correspondence: Dr Eoin Slattery, National Liver Transplant Unit, St Vincent's University Hospital, Dublin 4, Ireland.

Telephone 353-87-653-7077, fax 353-1-803-4770, e-mail slattery.eoin@gmail.com

Received for publication September 25, 2011. Accepted April 18, 2012 
Historically, advanced age has been considered a contraindication to liver transplant. However, there have been several reports that suggest that this should no longer be the case $(2,3)$. These studies suggest that outcomes in patients $>60$ years of age are comparable. Only one of these studies investigated patients $>65$ years of age (4). Cross et al (4) found equivocal differences with respect to age and survival postliver transplant in their well-selected cohort.

In recent years, OLT in patients $>65$ years of age has become widely accepted. Using the United Network for Organ Sharing (UNOS) registry, Waki (5) reported that $15.3 \%$ of all transplants performed in the United States were in patients $>65$ years of age. Despite this, controversies remain.

Our anecdotal experience to date would suggest that elderly age alone is not a contraindication to OLT, but differences do exist in subcohorts with regard to survival. Our aim was to review the outcomes of OLT in patients $>65$ years of age, with particular attention devoted to sex, and to compare their outcomes with patients $\leq 65$ years of age. Second, we sought to identify any factors that may provide valuable prognostic information regarding outcomes.

\section{METHODS}

\section{Patients}

Patients were identified by searching a prospectively maintained database of patients who underwent liver transplant in St Vincent's University Hospital, an Irish university hospital (Dublin, Ireland). St Vincent's is the Irish national referral centre for liver disease and the only liver transplant unit in the Republic of Ireland. Thus, it is uniquely placed to study the trends and outcomes of an entire country and is free from the referral bias that may adversely impact patient outcomes in other centres. The database was established in 1993, and contains demographic and clinical details of all patients who have undergone transplant since the inception of the unit in the same year.

Patients $>65$ years of age who underwent transplant between January 1993 and December 2009 were identified. Also identified were a similar number of patients from a general cohort (ie, between 18 and 65 years of age), who were matched to the elderly cohort according to sex and year of transplant.

All patients underwent a similar work-up with respect to preoperative comorbidities and fitness for OLT. Specifically, patients underwent routine history and physical examination. Cardiovascular health was assessed by electrocardiography and echocardiography. Coronary angiography and right heart studies were reserved for patients with abnormalities detected on routine assessment or for patients with preexisting heart disease. Respiratory function was assessed by chest $\mathrm{x}$-ray, and arterial blood gas and pulmonary function tests.

\section{Outcomes}

The medical records of these patients were reviewed. Outcomes in the two cohorts were studied; specifically, one- and three-year survival rates. Analyses between cohorts with respect to age and sex were also performed. Also compared between the two cohorts were standard preoperative variables of liver disease, namely, bilirubin, creatinine, sodium and albumin levels, and international normalized ratio, and Model for End-stage Liver Disease score (MELD) and Child-Pugh scores. Preoperative comorbidities were also recorded. Postoperative outcomes with respect to postoperative complications, acute cellular rejection, length of hospital stay and readmissions to the unit postdischarge were analyzed.

\section{End points}

The primary end point was survival at one and three years' post-liver transplant.

\section{Statistical analysis}

Statistical analysis was performed using SPSS version 15 (IBMCorporation, USA), with $\mathrm{P}<0.05$ considered to be statistically significant. Survival was compared using the Kaplan-Meier technique. Independent variables between the two groups were assessed using logistic regression analysis. Multivariate analysis was also performed.

\section{RESULTS}

Between January 1993 and December 2009, 551 patients underwent 639 transplants at the Irish National Liver Transplant Unit. Fortythree transplants were performed in 40 patients $>65$ years of age. These patients were matched with 43 patients between 18 and 65 years of age who underwent OLT over the same time period. Both emergency and elective procedures were included in the analysis.

All patients underwent cadaveric liver transplantation. Patients received immunosuppression according to contemporary protocols. Specifically, a calcineurin inhibitor- (initially cyclosporine, but later tacrolimus) based therapy with corticosteroids. Triple therapy (initially azathioprine but subsequently mycophenolate mofetil) was reserved for patients with previous rejection episodes or viral hepatitis. Cyclosporine trough levels were initially maintained at $150 \mu \mathrm{g} / \mathrm{L}$ to $250 \mu \mathrm{g} / \mathrm{L}$ and, after six months, a lower level of $100 \mu \mathrm{g} / \mathrm{L}$ was used. Prednisolone was given at a dose of $20 \mathrm{mg}$ per day and weaned to $5 \mathrm{mg}$ per day over three months in cases for which possible complete steroid withdrawal was attempted. Tacrolimus levels were maintained at $10 \mu \mathrm{g} / \mathrm{L}$ to $15 \mu \mathrm{g} / \mathrm{L}$ in the first six months and, thereafter, a level of $5 \mu \mathrm{g} / \mathrm{L}$ to $10 \mu \mathrm{g} / \mathrm{L}$ was accepted. Episodes of acute cellular rejection were treated with pulsed doses of methylprednisolone at a dose of $1 \mathrm{~g}$ per day for three days.

\section{Indication for OLT}

The most common indication for transplant in the elderly cohort was primary biliary cirrhosis $(n=8)$, followed by hepatocellular carcinoma $(n=7$ [due to predisposing etiologies of alcohol-related liver disease, hemochromatosis and alpha-1 antitrypsin deficiency]). Five patients underwent transplant for primary sclerosing cholangitis and an additional five underwent OLT for alcohol-related liver disease. Three patients were emergently transplanted for fulminant liver failure. Only one patient required a transplant for chronic hepatitis $\mathrm{C}$. The remaining 12 patients underwent OLT for a variety of miscellaneous reasons including cryptogenic cirrhosis, nonalcoholic fatty liver disease and sarcoid-related liver disease.

The indications in the general cohort (ie, between 18 and 65 years of age) differed from the elderly cohort. The most common indication for transplant in the younger group was for alcohol-related liver disease $(n=8)$, the next most common indication was for chronic hepatitis C (6). Six patients underwent transplant for hepatocellular carcinoma (the majority of which had alcohol-related liver disease as their major predisposing factor), while an additional six were emergently transplanted for fulminant liver failure. Three patients were transplanted for autoimmune hepatitis, three for primary biliary cirrhosis and an additional two for primary sclerosing cholangitis. The remaining nine patients underwent a transplant for miscellaneous reasons including Budd-Chiari syndrome, alpha-1 antitrypsin deficiency and cryptogenic cirrhosis.

\section{Survival}

Unadjusted one- and three-year survival rates for the elderly cohort were $77.8 \%$ and $64.5 \%$, respectively. This compared with $93 \%$ and $85 \%$, respectively, in the matched cohort. Survival curves are shown in Figure 1. Using Kaplan-Meier analysis, a statistically significant difference was seen between the cohorts $(\mathrm{P}=0.017)$. Elderly patients had a demonstrably poorer outcome when compared with their younger counterparts.

To assess for differences with respect to sex, a separate analysis on male and female patients with respect to age was performed. The survival curves are presented in Figures 2 and 3. Figure 3 shows that there was no difference with respect to survival in women $>65$ years of age compared with their younger counterparts $(\mathrm{P}=0.424)$. However, a clear difference was noted between men with respect to age (Figure 2). A statistically significant difference in survival was seen in male 


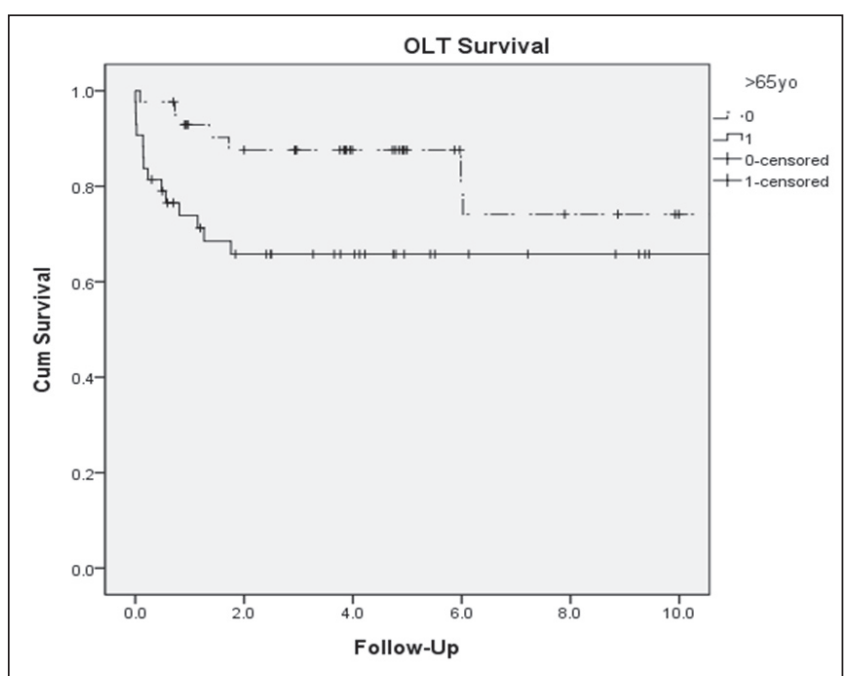

Figure 1) Kaplan-Meier curve demonstrating significant survival differences between patients $\leq 65$ years of age (yo) and patients $>65$ yo undergoing orthotopic liver transplant $(\mathrm{OLT})(P=0.017)$. Cum Cumulative

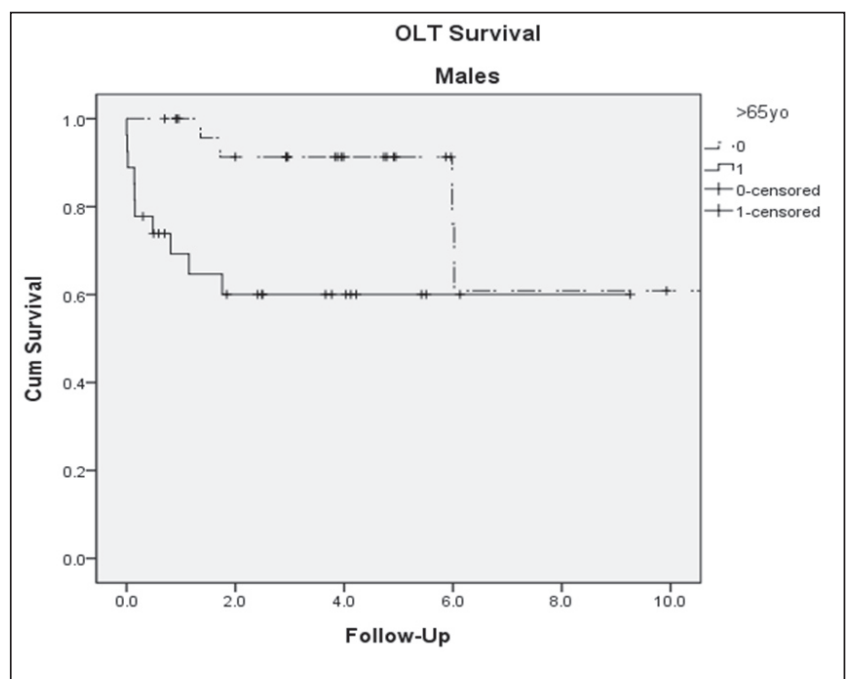

Figure 2) Kaplan-Meier curve demonstrating a significant difference with respect to survival in men $\leq 65$ years of age (yo) and patients $>65$ yo undergoing orthotopic liver transplant $(\mathrm{OLT})(P=0.020)$. Cum Cumulative

patients $(\mathrm{P}=0.020) \leq 65$ years of age compared with a worse outcome in the elderly cohort.

\section{Preoperative variables}

The standard preoperative variables with respect to severity of underlying liver disease were compared, the results of which are shown in Table 1. No difference was seen between the cohorts in any of these variables (ie, bilirubin, creatinine, albumin and sodium levels, and international normalized ratio and MELD score).

A multivariate subanalysis also showed no difference in preoperative variables between elderly men and all other patients.

\section{Postoperative outcomes}

Postoperative outcomes (independent of survival) were assessed in both cohorts - specifically, hospital length of stay and occurrence of acute cellular rejection; these data are summarized Table 2. Again, no differences were noted between the two cohorts.

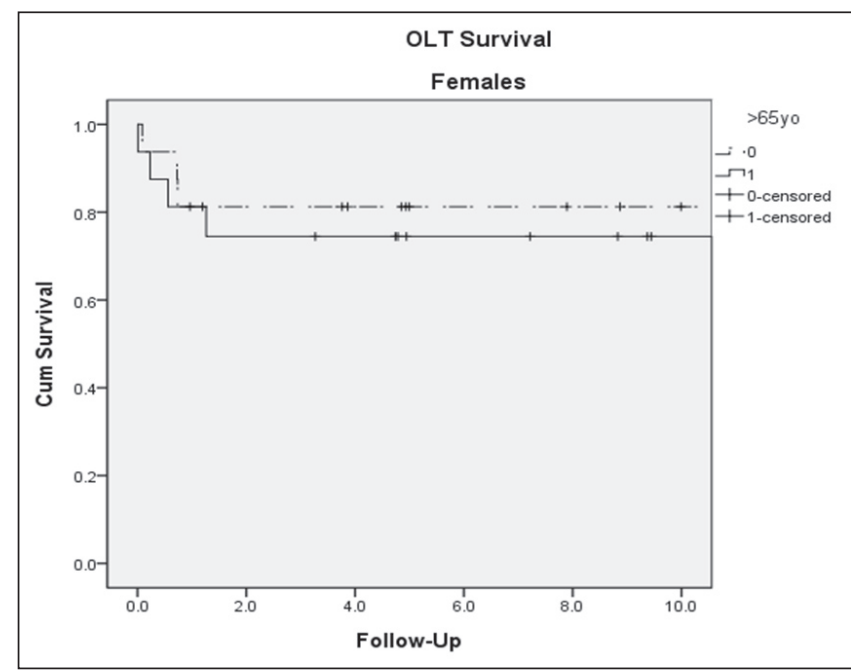

Figure 3) Kaplan-Meier curve demonstrating no significant difference with respect to survival in women $\leq 65$ years of age (yo) or $>65$ yo undergoing orthotopic liver transplant $(\mathrm{OLT})(P=0.424)$. Cum Cumulative

TABLE 1

Comparison of preoperative variables according to severity of liver disease before liver transplant

\begin{tabular}{lccc}
\hline Preoperative & \multicolumn{2}{c}{ Cohort (age, years) } & \\
\cline { 2 - 3 } variable & $\mathbf{A ~ ( \leq 6 5 )}$ & $\mathbf{B}(>65)$ & $\mathbf{P}^{*}$ \\
\hline Bilirubin, $\mu \mathrm{mol} / \mathrm{L}$ & 45.5 & 56 & 0.89 \\
International normalized ratio & 1.24 & 1.40 & 0.54 \\
Creatinine, $\mu \mathrm{mol} / \mathrm{L}$ & 98 & 84 & 0.64 \\
Sodium, $\mathrm{mmol} / \mathrm{L}$ & 136 & 137 & 0.78 \\
Albumin, g/L & 30 & 27 & 0.18 \\
MELD score & 15 & 14 & 0.71 \\
\hline
\end{tabular}

${ }^{*} P<0.05$ considered to be statistically significant. MELD Model for End-stage Liver Disease

TABLE 2

Comparison of postoperative outcomes between the two cohorts, independent of survival

\begin{tabular}{lccc}
\hline \multirow{2}{*}{ Outcome } & \multicolumn{2}{c}{ Cohort (age, years) } & \multirow{2}{*}{ P* } \\
\cline { 2 - 3 } & $\mathbf{A ~ ( \leq 6 5 )}$ & $\mathbf{B}(>65)$ & \\
\hline Length of hospital stay, days, median & 23 & 24.5 & 0.89 \\
Length of stay $>$ 30 days, n (\%) & $19(44.2)$ & $16(37.2)$ & 0.52 \\
Acute cellular rejection, $\mathrm{n}(\%)$ & $18(41.9)$ & $17(39.5)$ & 0.83 \\
\hline
\end{tabular}

${ }^{*} P<0.05$ considered to be statistically significant

\section{Comorbidities}

The presence of comorbidities in the cohorts was assessed. There was no difference between the cohorts with regard to the presence or absence of a single comorbidity. Patients who had more than one comorbidity (eg, presence of diabetes mellitus and hypertension, etc) were subsequently analyzed. Three $(7 \%)$ patients in the younger cohort and $11(25.6 \%)$ patients in the older cohort were found to have more than one comorbidity; this difference was found to be statistically significant $(\mathrm{P}=0.024)$.

\section{DISCUSSION}

The evidence for excluding patients $>65$ years of age from consideration for OLT is contradictory $(4,6-9)$. Here, we report on our experience with OLT in an elderly cohort compared with the general OLT recipient population. We demonstrated significantly poorer survival in patients $>65$ years of age, particularly with respect to elderly males. We 
matched patients according to year of transplant and to sex to control for differences in practice with respect to immunosuppression and standard postoperative care that have occurred over time.

Indications for OLT between the two cohorts were different. The younger cohort had more patients with hepatitis $\mathrm{C}$ or alcohol-related causes of their underlying liver disease. Not surprisingly, elderly patients had a higher incidence of hepatocellular carcinoma or autoimmune diseases. This was to be expected and has been previously reported (5). Despite this, both cohorts were similar with respect to preoperative severity of liver disease, as indicated by similar MELD scores (15 versus 14), and nonsignificant differences between bilirubin, creatinine and sodium levels. Thus, the cohorts would appear to have been reasonably matched.

Outcomes with respect to sex have never been studied in an elderly cohort of liver transplant patients. There is some evidence to suggest that women of an advanced age fare better than their male counterparts with regard to general surgical outcomes, although advancing age alone was a more significant predictor of mortality in this cohort (10). We showed that women $>65$ years of age have similar outcomes to their younger counterparts. It would seem that the overall difference in survival noted in our group appears to relate to the poorer outcomes in male patients $>65$ years of age.

Furthermore, the presence of one or more comorbidities was the only preoperative predictor that we could identify that was associated with a worse outcome.

Interestingly, episodes of acute cellular rejection were similar. It has previously been reported that older age is associated with fewer episodes of rejection due to immune senescence (3). This was not observed in our cohort.

\section{REFERENCES}

1. Prakoso E, Verran D, Dilworth P, et al. Increasing liver transplantation waiting list mortality: A report from the Australian National Liver Transplantation Unit, Sydney. Intern Med J 2010;40:619-25.

2. Adani GL, Baccarani U, Lorenzin D, et al. Elderly versus young liver transplant recipients: Patient and graft survival. Transplant Proc 2009;41:1293-4.

3. Collins BH, Pirsch JD, Becker YT, et al. Long-term results of liver transplantation in older patients 60 years of age and older. Transplantation 2000;70:780-3.

4. Cross TJS, Antoniades CG, Muiesan P, et al. Liver transplantation in patients over 60 and 65 years: An evaluation of long-term outcomes and survival. Liver Transpl 2007;13:1382-8.

5. Waki K. UNOS Liver Registry: Ten year survivals. Clin Transpl 2006:29-39.
Clearly, organ allocation and resource utilization are important topics in the transplant process. Similarly, outcomes (particularly survival) are also crucial end points. Our evidence suggests that advanced age remains an important component in the assessment of patients for transplant at our centre. This was particularly evident in the poorer survival rate of elderly men. As mentioned previously, reports on outcomes for elderly patients have varied. It has been suggested that an important variable in the published reports relates to the extensiveness of pretransplant assessment. Bilbao et al (8) reported their outcomes in elderly transplant recipients and found poorer survival in an elderly cohort, similar to the cohort described here. However, they also note that once patients are carefully selected, older patients appeared to experience similar outcomes. Audet et al (9) suggested that cardiac preassessment is particularly important in the elderly transplant recipient. Our study shows, for the first time, that sex may also be an important consideration in the pretransplant assessment of elderly patients.

Clearly, our study was small and lacking significant statistical power and, therefore, one must be cautious not to overinterpret the data. We would suggest that while our work needs to be validated in larger cohorts (eg, United Kingdom Transplant/UNOS, etc), a cautious approach to the pretransplant work-up in elderly patients is warranted. Individual and relatively minor comorbidities may not lead to exclusion from transplant, but may have an aggregate effect on preoperative and, more importantly, postoperative, physical well-being.

We believe that our experience supports the view that multiple comorbidities in elderly men should be thoroughly assessed and, if validated elsewhere in larger cohorts, may become a relative contraindication in patients being assessed for OLT.

6. Levy MF, Somasundar PS, Jennings LW, et al. The elderly liver transplant recipient: A call for caution. Ann Surg 2001;233:107-13.

7. Aduen JF, SujayB, Dickson RC, et al. Outcomes after liver transplant in patients aged 70 years or older compared with those younger than 60 years. Mayo Clin Proc 2009;84:973-8.

8. Bilbao I, Dopazo C, Lazaro JL, et al. Our experience in liver transplantation in patients over $65 \mathrm{yr}$ of age. Clin Transplant 2008;22:82-8.

9. Audet M, Piardi T, Panaro F, et al. Liver transplantation in recipients over $65 \mathrm{yr}$ old: A single center experience. Clin Transplant 2010;24:84-90.

10. Massarweh NN, Legner VJ, Symons RG, et al. Impact of advancing age on abdominal surgical outcomes. Arch Surg 2009;144:1108-14. 


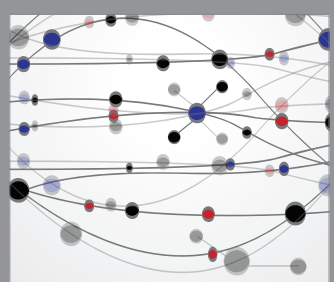

The Scientific World Journal
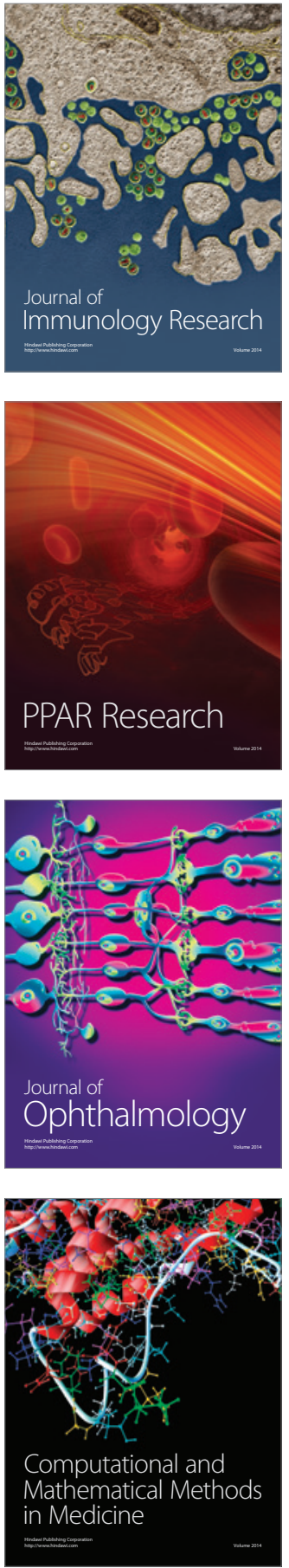

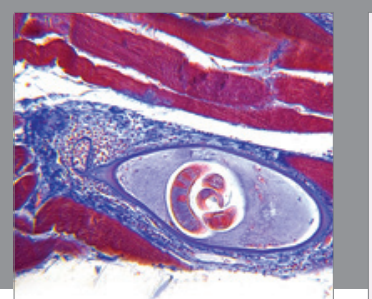

Gastroenterology Research and Practice

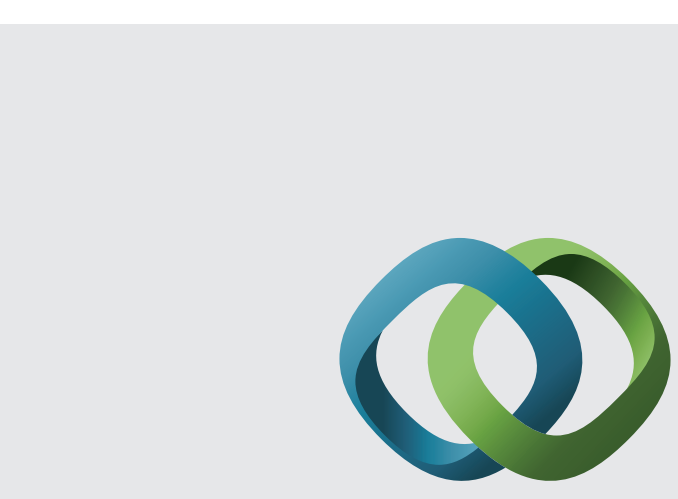

\section{Hindawi}

Submit your manuscripts at

http://www.hindawi.com
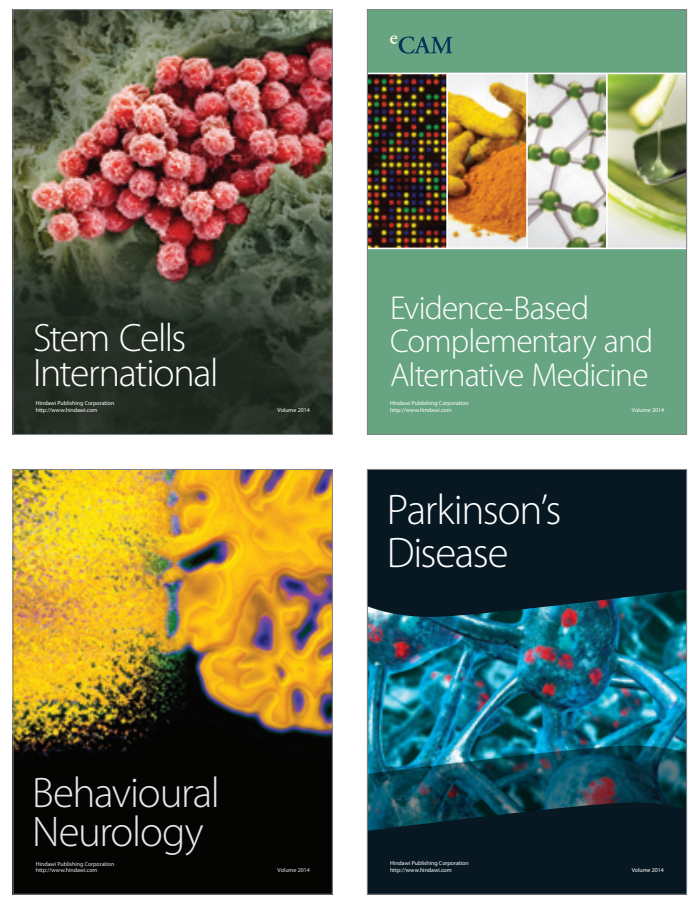
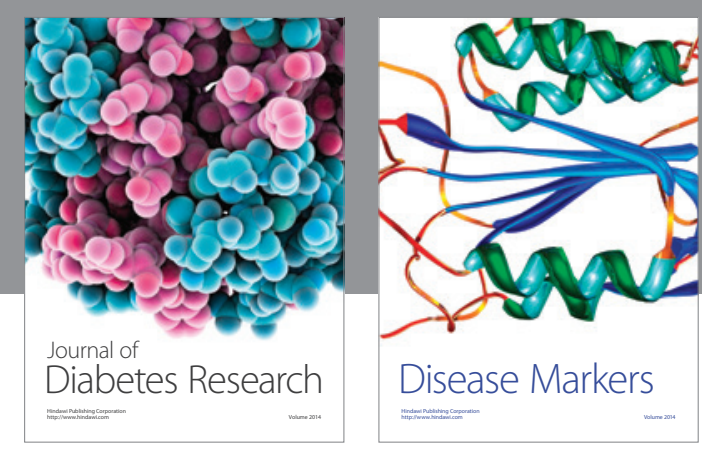

Disease Markers
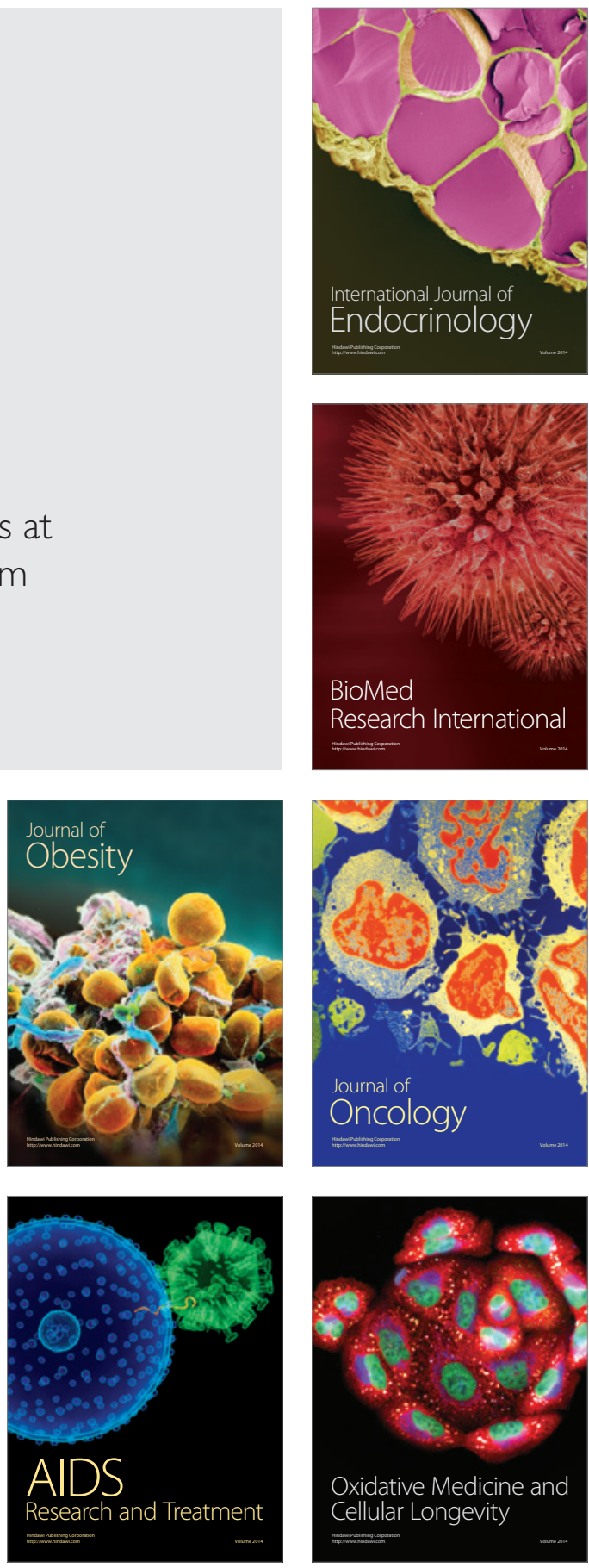